\title{
Comparative analysis of automatic transmission and manual transmission behaviour on the worldwide harmonized light duty test cycle
}

\author{
Norbert Bagameri ${ }^{1}$, Bogdan Varga ${ }^{1}$, Aron Csato $^{1}$ and Dan Moldovanu ${ }^{1, *}$ \\ ${ }^{1}$ Technical University of Cluj-Napoca, Automotive and Transport Department, 400641 Cluj-Napoca, Romania
}

\begin{abstract}
The European Commission has been actively involved in the development of the World-wide harmonized Light duty Test Cycle (WLTC). The aim of that project was to develop a harmonized light duty test cycle, that represents the average driving characteristics around the world and to have a legislative world-wideharmonized procedure put in place from 2017 and onwards for determining the level of $\mathrm{CO}_{2}$ emissions. This work presents the results of the effect of automatic and manual transmissions as a drivetrain of a light duty vehicle on WLTC driving cycle. AVL Cruise software was used as simulation platform to analyse the $\mathrm{CO}_{2}$ level and fuel consumption of dynamic vehicle model using different type of drivetrains. At first the simulation tool and the most influential parameters of the driving cycle procedure are described. In the second phase various components and modules for both dynamic models using automatic and manual transmission, as well as the respective input parameters, were defined. Analyses are based on a developed dynamic vehicle model in AVL Cruise. Finally, the simulation results were evaluated and presented for the two dynamic models according to a legislative driving cycle to provide the basis fuel consumption and exhaust gas emissions.
\end{abstract}

\section{Introduction}

Recently research and development trends in the automotive industry have been focused on developing vehicles with drivetrains that are strongly driven by steadily increasing demands on improvements in fuel consumption, emissions and performance. The transportation sector is currently responsible for over $20 \%$ of emission of greenhouse pollutants, emissions that directly affect the climatic conditions of the planet. Increased emissions in conjunction with achieving the maximum degree of natural regeneration of the environment lead to serious problems related to pollution $[1,2]$. Since the early phase of the automotive development, the interaction between the environment and the traffic has been represented by an ever-increasing number of legal standards related to reducing the exhaust gas pollutants, hazardous substances and waste. The increasingly high traffic density, high demand of mobility and transportation adversely have a significant impact on the environment, causing the large societal problems such as a rapid depleting petroleum resources, an increasing air pollution and global warming [3].

The European Union automobile industry welcomes the shift to WLTC and has actively contributed to the development of this new test cycle.

\section{Driving cycle procedure}

The European Union has developed a new test, called the Worldwide Harmonised Light Vehicle Test Cycle (WLTC). The WLTC has been developed with driving profile obtained from in use driving data and a test procedure more realistic in terms of vehicle mass and resistance to progress. The New European Driving cycle (NEDC) significantly differs from WLTC characterized by a shorter duration and distance, longer idling and cruising time and lower speed and acceleration. Although WLTC driving cycle profile is more transient than NEDC, when these two cycles are tested under the same driving resistance. In WLTC are taking into account its minimum and maximum unladen mass, which is defined as the vehicle's standard weight without driver, fluid or any additional equipment, the maximum permissible weight, the difference in rolling resistance between different tire versions, as well as the difference in aerodynamic resistance expressed as the product of the drag coefficient and the frontal area between vehicle model with the best and worst aerodynamics. Because pollutant emissions from vehicles are caused by combustion of a fuel generally fossil fuels, increasing the efficiency and effectiveness of vehicles drivetrain is constantly the focus

\footnotetext{
* Corresponding author: dan.moldovanu@auto.utcluj.ro
} 
of attention of researchers from the automotive industry [2]. The objective of WLTC was to provide a more robust test-basis and a procedure which is more representative of actual on-road vehicle operation. WLTP significantly differs from NEDC, its main differences affecting fuel consumption include the test cycle and gear-shifting sequence, vehicle mass definition, road load determination, chassis dynamometer preconditioning [3, $4]$.

\section{Simulation software package}

Modelling various natural or artificial processes and phenomena in engineering is achieved by applying and performance of complex mathematical models. Using the AVL Cruise software simulations can be developed, controlled and coordinated at the same time to achieve results and solutions to optimize and improve the performance of vehicle's technical system and are analysed in terms of performance and operating efficiency. In order to quantify and analyse the effect of the drivetrain in the emissions and fuel consumption on WLTC driving cycle simulations were performed on two different transmissions. Fig. 1 represents the WLTC driving cycle.

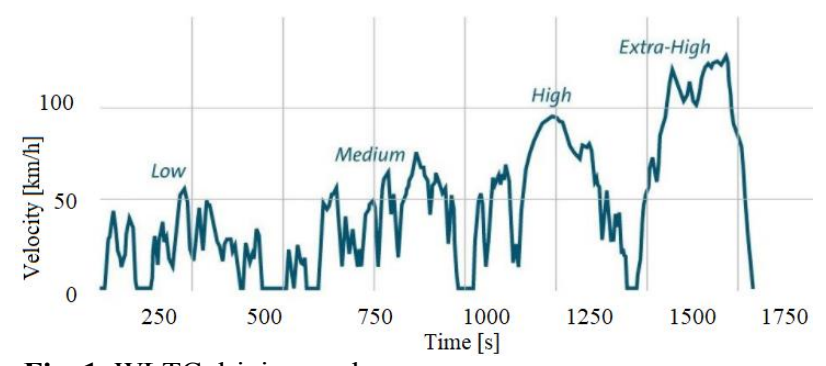

Fig. 1. WLTC driving cycle.

\section{Model description}

In the following paragraph provide a description of the drivetrains used for vehicles: with manual transmission and automatic transmission. The vehicle model includes the various sub-models. The vehicle model is a structure that has been developed to simulate accurately the two types of drivetrains. They are not different in the arrangement of components of the drivetrain. The developed model consists of components that exist in vehicles, such as the internal combustion engine, transmission, control and program of the transmission, brake system, steering system, wheels and the respective connections among them which can be either mechanical or electrical. Each component is described by several parameters and is configurable in such a way that it can represent a vehicle for this study. The main components of the simulation model with reference to Fig. 2, are the internal combustion engine and the attached mechanical consumer, manual/automatic transmission together with the controller that controls the operation of the gearbox such as the gearshift schedule, the differential together with the final drive, the brakes, the cockpit, the vehicle body, the electrical system which includes the battery and other modules essential for initiating the simulation. The
Transmission Controller of Dual Clutch Transmission consists of shift state controller, which preselects the gear according to the current and desired vehicle speed, which can be characterized by gearshift schedule.

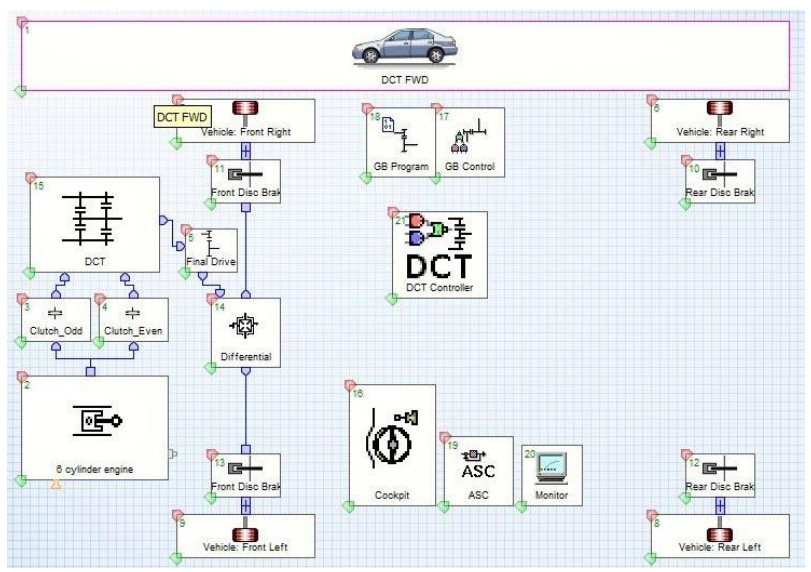

Fig. 2. AVL Cruise component model of the vehicle.

This simulation model was developed based on an existing vehicle using technical data provided by the manufacturer to simulate and to put in evidence the advantages and disadvantages of the drivetrain powered a front wheel drive vehicle equipped with manual transmission and with automatic dual clutch transmission. After every component of the vehicle model is set up the model is tested on the WLTC driving cycle. The basic parameters of the vehicle model are given in Table 1.

Table 1. DCT Vehicle model parameters

\begin{tabular}{|c|c|}
\hline Parameters & Value \\
\hline Vehicle mass & $1490[\mathrm{~kg}]$ \\
\hline Engine displacement & $2497\left[\mathrm{~cm}^{3}\right]$ \\
\hline Engine maximum power & $160[\mathrm{~kW}]$ \\
\hline Engine maximum speed & $6500[\mathrm{rpm}]$ \\
\hline Engine Inertia & {$\left[\mathrm{kg} / \mathrm{m}^{2}\right]$} \\
\hline Final drive ratio & $3.27[-]$ \\
\hline Clutch 1 inertia & {$\left[\mathrm{kg} / \mathrm{m}^{2}\right]$} \\
\hline Clutch 2 inertia & {$\left[\mathrm{kg} / \mathrm{m}^{2}\right]$} \\
\hline Frontal area & $1.88\left[\mathrm{~m}^{2}\right]$ \\
\hline Drag coefficient & $0.32[-]$ \\
\hline
\end{tabular}

Final drive is a gear step with fixed ratio. It can be used as a transmission step of the differential also called final drive unit. A drive torque will be transferred to a power take of torque of the transmission step by considering the transmission, the mass moments of inertia, and the moment of loss $[4,5]$. The gear ratios of the transmissions are given in the Table 2 .

Table 2. Gear ratio

\begin{tabular}{|c|c|}
\hline Gear & Gear ratio \\
\hline $1^{\text {st }}$ & 4.325 \\
$2^{\text {nd }}$ & 2.689 \\
$3^{\text {rd }}$ & 1.746 \\
$4^{\text {th }}$ & 1.25 \\
$5^{\text {th }}$ & 0.942 \\
$6^{\text {th }}$ & 0.721 \\
$\mathrm{R}$ & 1.0 \\
\hline
\end{tabular}


The driver should imitate the behaviour of a real driver as well as possible. Everything that would normally be controlled by a real driver, such as turning the steering wheel, stepping on the gas, brake and clutch pedal, shifting gears on the manual transmission is controlled by the virtual driver. As the driver controls the clutch pedal, it is necessary to express the clutch position as a function of time during clutch engagement phase [4].

\section{Drivetrain of the vehicle}

Two different transmission types were evaluated, one of the is the conventional manual transmission which has a limited number of gears, maximum up to six and the automatic transmission using two clutches, one for the odd gears and one for the even gears. In case of the manual transmission the entire synchronization process can be divided in nine stages Stage 1: free travel from neutral position, which has no torque transfer. This stage can also start from a disengagement from a previous gear called here as start of disengagement; Stage 2: beginning of the contact among strut and synchronization ring, initiating the indexing process or preselecting; Stage 3: indexing process concluded; Stage 4: contact of synchronization ring with the sleeve cone, initiating the synchronization phase; Stage 5: end of synchronization ring blocking and beginning of ring and gear turn due to cone friction; Stage 6: second free travel; Stage 7: tip contact of the sleeve against the gear clutch washer. In this stage is possible to detect the double bump phenomena; Stage 8: end of gear angular movement; Stage 9: full engagement $[5,6]$. In the following in Fig. 3 the shifting schedule is presented for the upshift and downshift process.

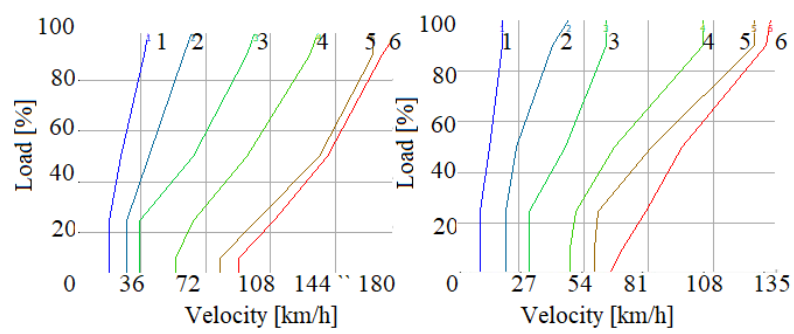

Fig. 3. Shifting strategy for upshift and downshift.

\section{Simulation and results}

Simulation were performed to investigate the vehicle fuel consumption and emission over time based driving cycle. The simulation is a method used to verify a model which represents the behaviour of a physical system. The maximum distance is 23266 meters and average speed of $46,5 \mathrm{~km} / \mathrm{h}$, maximum acceleration $5,66 \mathrm{~m} / \mathrm{s}^{2}$ and total time is 1800 seconds The fuel economy for dual clutch transmission is lower with $3.43 \%$ than the manual transmission over the WLTC driving cycle due to the elimination of torque interruption that is associated with manual transmission. The gearbox program is the same for the manual and dual clutch transmission and the gear shifting time is $500 \mathrm{~ms}$ for manual transmission and $8 \mathrm{~ms}$ for dual clutch transmission. Due to the different working conditions of the gearboxes the automatic transmission operates frequent gear changes, 22 more operations over the WLTC cycle than the manual transmission.

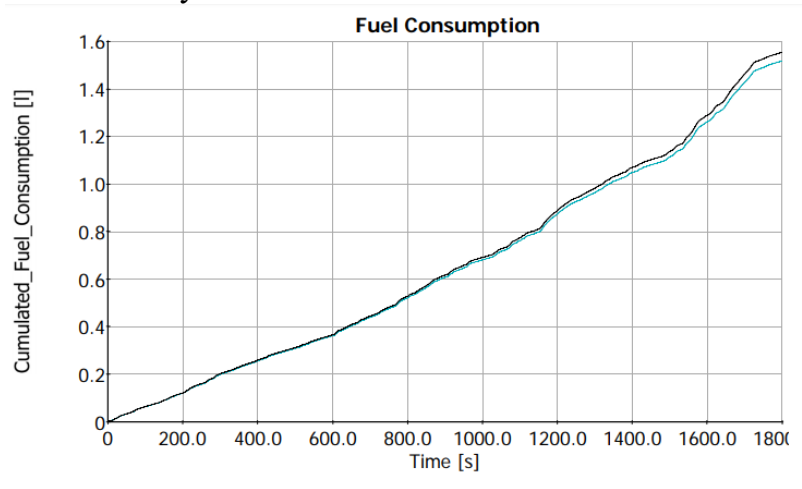

Cumulated Fuel Consumption manual transmission from 1: Manual transmission Cumulated_Fuel_Consumption manual transmission from 2: DCT transmission

Fig. 4. Variation of the fuel consumption during WLTC driving cycle

In the simulation carried out with AVL Cruise WLTC regulation fixed points, the total $\mathrm{CO}$ emissions were found higher by $6 \%$ higher for the case using automatic dual clutch transmission than using the manual transmission vehicle when compared to the WLTC CO emissions curve.

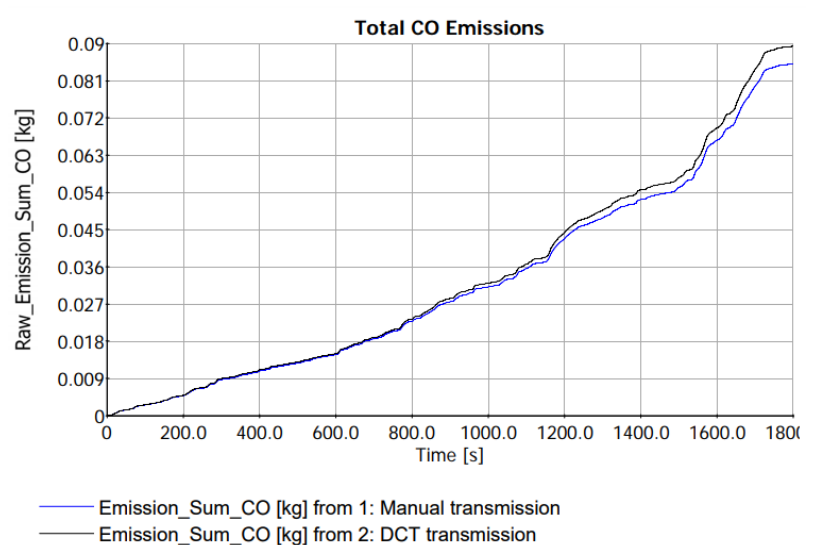

Fig. 5. Variaton of CO emissions over the WLTC driving cycle.

In the Fig. 6 it can be seen that the maximum value of the $\mathrm{HC}$ emissions is $0.015[\mathrm{~kg}]$ and it is achieved using the manual transmission due to the higher load of the internal combustion engine and different gear shift strategy of the transmission. 


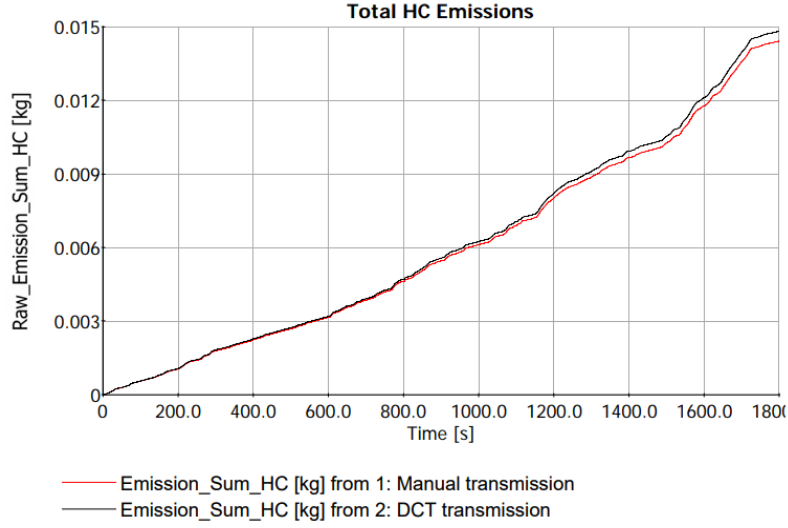

Fig. 6. Variaton of HC emissions over the WLTC driving cycle.

It is seen in the figure that especially there is a significant increase in the $\mathrm{NO}_{\mathrm{x}}$ emission in the high speed area of the driving cycle due to the higher temperature into the combustion chamber and higher speed of the internal combustion engine using a lower gear ratio.

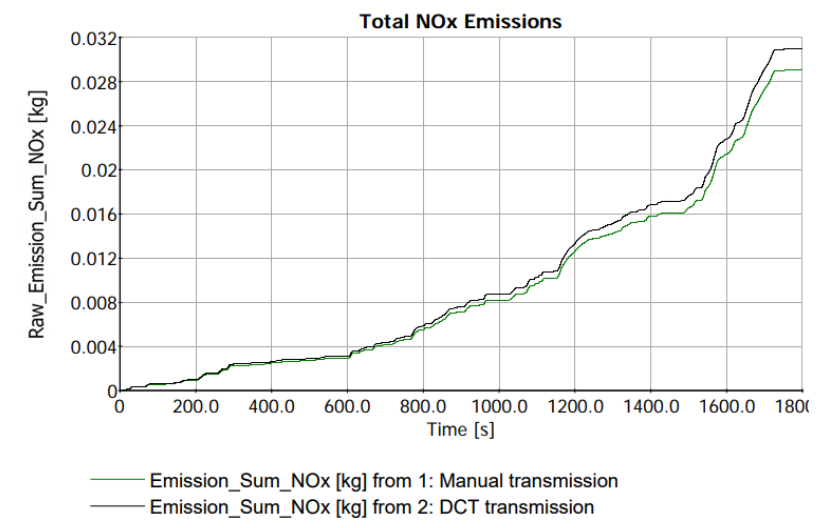

Fig. 7. Variaton of $\mathrm{NO}_{\mathrm{x}}$ emissions over the WLTC driving cycle.

The Fig. 8 shows the necessary power of the engine to drive the vehicle during WLTC driving cycle. During low speed sector (0-589s), medium speed part (589-1022s), high speed sector (1022-1477s) and the extra high speed sector (1477-1800s) the average power requirements of vehicle is $24 \mathrm{Nm}$ for the vehicle model with automatic dual clutch transmission and $27 \mathrm{Nm}$ for the one with manual transmission.

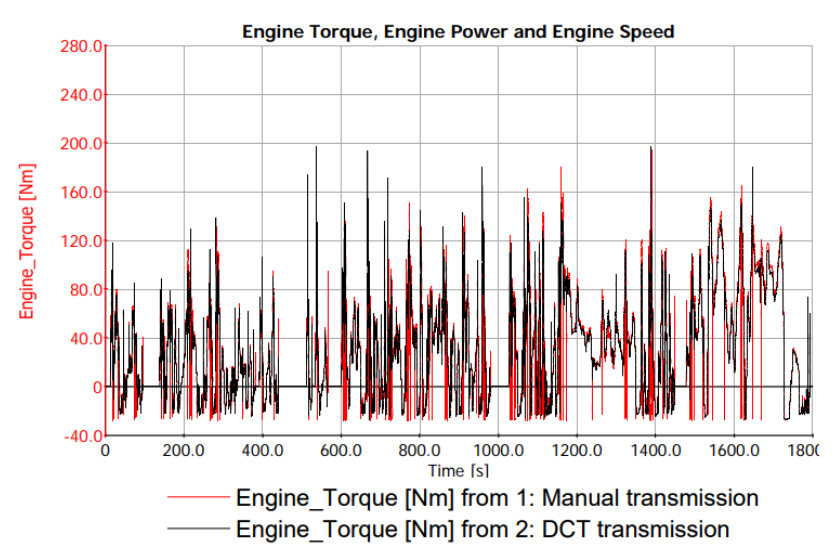

Fig. 8. Variaton of engine power necessary for propulsion the vehicel

\section{Conclusion}

Simulation software can significantly reduce the time required for developing new technologies and control strategies in the automotive field. The overall system engineering model is used to compare the two drivetrains topologies powered by the same engines during WLTC driving cycle. This investigation focuses on evaluation of the fuel consumption, emissions of the considered vehicle configuration. Finally simulation results demonstrates the differences of using two type of drivetrains for the vehicle and the importance of considering also the automatic dual clutch transmission in order to achieve lower fuel consumption and emissions.

\section{Reference}

1. B. Himadri, A. Simos, D. Samraj, "An objective analysis of drivability for two wheeler powertrain with control oriented dynamic model," IFAC-PapersOnLine 48-15, 292-299, 2015.

2. K. Sangmyeong, K. Jinsu, G. Sung, J. Lee, "Evaluation and development of improved braking model for a motor-assisted vehicle using MATLAB/simulink." Journal of Mechanical Science and Technology No.29, pp.2747-2754, 2015.

3. E. Luciano, T. Plinio, "Human Factors Analysis of Manual Gear shifting Performance in Passanger Vehicles," Procedia - Social and Behavioral Sciences, Vol.3, pp. 4350-4357, 2015.

4. X. Xiaohui "Shifting Control and Analysis of Dual Clutch Transmission of Automobile." International Journal of Control and Automation Vol.8, No.12, pp.241-252, 2015.

5. T. Stefanos, G. Fontaras, C. Biagio, Z. Samaras "A simulationbased methodology for quantifying European passenger car fleet $\mathrm{CO}_{2}$ emissions." International Journal of Applied energy Vol.199, pp.447-465, 2017.

6. B. O. Varga, F. Mariașiu, D. Moldovanu, C. Iclodean"Electric and Plug-in Hybrid Vehicles - Advanced Simulation Methodologies", Springer International Publishing Ed., ISBN: 978-3-319-18638-2, 2015. 